\title{
Efficient perovskite nanocrystal light-emitting diodes using a benzimidazole-substituted anthracene derivative as the electron transport material $\dagger$
}

\author{
Sudhir Kumar, (D) a Tommaso Marcato, ${ }^{a}$ Serhii I. Vasylevskyi, (D) b Jakub Jagielski, (D) a \\ Katharina M. Fromm (iD *b and Chih-Jen Shih (iD *a \\ Colloidal nanocrystals of organic-inorganic hybrid perovskites (OIHPs) are an emerging class of solid- \\ state lighting materials owing to their outstanding photophysical properties. Considerable research \\ efforts have been devoted to the fabrication of high-performance light-emitting diodes (LEDs) based on \\ these materials, including interface engineering which is essential for balancing the electron and hole \\ injection in devices. Here, we report efficient perovskite nanocrystal LEDs based on a new electron \\ transport material (ETM), 9,10-bis( $N$-benzimidazolyl)anthracene (BBIA), possessing a high electron \\ mobility of $4.17 \times 10^{-4} \mathrm{~cm}^{2} \mathrm{~V}^{-1} \mathrm{~s}^{-1}$ at an electric field of $10^{5} \mathrm{~V} \mathrm{~cm}^{-1}$. Compared to control devices \\ based on the ETM 2,2',2" -(1,3,5-benzinetriyl)-tris(1-phenyl-1-H-benzimidazole) (TPBi), BBIA-based \\ devices exhibit a nearly two-fold enhancement, increasing the current and external quantum efficiencies \\ from $6.25 \mathrm{~cd} \mathrm{~A}^{-1}$ and $1.51 \%$ to $12.2 \mathrm{~cd} \mathrm{~A}^{-1}$ and $2.96 \%$, respectively. In addition, a small degree of \\ efficiency roll-off of $8 \pm 1 \%$ at a luminance of $2000 \mathrm{~cd} \mathrm{~m}^{-2}$, as well as a low turn-on voltage of $2.35 \mathrm{~V}$, \\ has been demonstrated. The anthracene-based compounds may open up new research opportunities \\ for interface engineering in perovskite LEDs.
}

\section{Introduction}

In the past decade, we have witnessed unprecedented development of organic-inorganic hybrid perovskite- (OIHP-) based optoelectronic devices. ${ }^{1,2}$ OIHP materials combine solution processability, tunable bandgap, narrowband emission, and facile synthesis, which makes them very promising for next-generation lighting and displays. ${ }^{3-6}$ Recent research efforts have focused on the enhancement of their LED performance, ${ }^{7-9}$ as reflected by the demonstration of ultrahigh external quantum efficiencies $\left(\eta_{\text {ext }}>20 \%\right),{ }^{10-13}$ based on the bulk and quasi-2D forms of OIHP thin films. We notice that high efficiency devices have been realized in both bromide and iodide systems using bulk polycrystalline or quasi-2D/3D mixed films; yet it remains controversial if the observed high efficiencies can be extended to cover the entire visible spectrum. ${ }^{14}$ In this respect, colloidal nanocrystals, or colloidal quantum dots (CQDs), of OIHPs may be an

${ }^{a}$ Institute for Chemical and Bioengineering, Department of Chemistry and Applied Biosciences, ETH Zurich, Vladimir-Prelog-Weg 1-5/10, CH-8093 Zurich, Switzerland. E-mail: chih-jen.shih@chem.ethz.ch

${ }^{b}$ Department of Chemistry, University of Fribourg, Ch. du Musée 9, 1700 Fribourg CH-1700 Fribourg, Switzerland. E-mail: katharina.fromm@unifr.ch

$\dagger$ Electronic supplementary information (ESI) available. See DOI: 10.1039/c9tc02352f interesting alternative. On the one hand, the emission wavelength can be precisely tuned with two degrees of freedom, namely by ionic doping and quantum confinement. On the other hand, the photoluminescence (PL) quantum yields $\left(\eta_{\mathrm{PL}}\right)$, the upper limit of the internal quantum efficiency in devices, can reach unity. ${ }^{5,15}$ Unfortunately, to date, their LED performance remains on the relatively low side. ${ }^{7,16-18}$

The mechanisms lowering the efficiency of perovskite nanocrystal-based devices are still not very well-understood. ${ }^{19-23}$ Several possible causes have been proposed, including (i) nonradiative recombination losses due to the surface defects on the nanocrystal surface,$^{23-27}$ (ii) the leakage current induced by the incomplete surface coverage, ${ }^{28,29}$ and (iii) the imbalance of carrier injection that results in a high degree of efficiency rolloff at high luminance. ${ }^{13}$ In this report, we aimed to address the last point. A possible mechanism leading to imbalanced charge injection is due to the fact that the electron mobility in organic semiconductors is usually orders of magnitude lower than the hole mobility. ${ }^{30-32}$ It is therefore desirable to employ high electron mobility ETMs, ${ }^{33}$ with a deep highest occupied molecular orbital (HOMO) energy blocking the hole transport, ${ }^{34,35}$ and an appropriate lowest unoccupied molecular orbital (LUMO) energy in favor of electron injection. ${ }^{36}$ Besides hole transport materials (HTMs) having a shallow LUMO and a comparable hole mobility, ${ }^{37-39}$ they allow 
radiative recombination events to take place in the middle of the emission layer, thereby minimizing the efficiency roll-off at a high carrier concentration. Recently, a number of ETM compounds have been used in perovskite LEDs, such as TPBi, ${ }^{7,23}$ B3PYMPM, ${ }^{21}$ BPhen, ${ }^{40}$ BCP, ${ }^{41}$ TmPyPB, ${ }^{42}$ 3TPYMB, ${ }^{19}$ and PO-T2T. ${ }^{2,43}$ In this report, we examine the performance of 9,10-bis( $N$-benzimidazolyl)anthracene (BBIA) as an ETM in perovskite nanocrystal LEDs.

\section{Results and discussion}

Perovskite nanocrystals with chemical formula $\mathrm{FA}_{0.5} \mathrm{MA}_{0.5} \mathrm{PbBr}_{3}$, where $\mathrm{FA}=$ formamidinium, $\mathrm{CH}_{3}\left(\mathrm{NH}_{2}\right)_{2}{ }^{+}$, and $\mathrm{MA}=$ methylammonium, $\mathrm{CH}_{3} \mathrm{NH}_{3}{ }^{+}$, were synthesized at room temperature using the ligand-assisted reprecipitation (LARP) technique. ${ }^{19,20}$ Fig. 1 shows the photograph of the colloidal solution under ultraviolet (UV) illumination and the transmission electron micrograph (TEM) of the nanocrystals. The absolute $\eta_{\mathrm{PL}}$ values were determined to be $86 \%$ and $95 \%$ for the solution and thin-film samples, respectively. We attribute the higher $\eta_{\mathrm{PL}}$ in the thin film sample to aggregation-induced emission (AIE) phenomena illustrated by our group. ${ }^{6}$ The thin-film photoluminescence shows a narrow-band emission peak centered at $528 \mathrm{~nm}$, with a full width at half maximum (FWHM) of $23.5 \pm 0.5 \mathrm{~nm}$ (Fig. S1, $\mathrm{ESI} \dagger$ ). The thin-film X-ray diffraction (XRD) patterns of perovskite nanocrystals are shown in Fig. S2 (ESI $\dagger$ ). We observe diffraction peaks at $15.375^{\circ}, 30.425^{\circ}, 45.975^{\circ}$, and $62.575^{\circ}$, corresponding to the (001), (002), (003) and (004) planes, respectively. ${ }^{44}$ The (011) and (012) plane peaks at $21.525^{\circ}$ and $34.025^{\circ}$, respectively, are relatively weak, presumably suggesting that the nanocrystals may be of the nanoplatelet symmetry, as we reported previously. ${ }^{45,46}$

The BBIA molecule is synthesized by the modified Ullmann coupling reaction ${ }^{47}$ (Scheme 1) by reacting 9,10-dibromoanthracene and benzimidazole in the presence of anhydrous potassium hydroxide and dried dimethylformamide (DMF) at $120{ }^{\circ} \mathrm{C}$ under an argon (Ar) atmosphere for $24 \mathrm{~h}^{48}$ BBIA was purified by column chromatography using THF/hexane $10: 1$ as an eluent, giving a greenish powder at a yield of $68 \%$. The product was characterized by ${ }^{1} \mathrm{H}$ - and ${ }^{13} \mathrm{C}-\mathrm{NMR}$, indicating at least $98 \%$ purity powder diffraction of BBIA gave identical unit cells compared to the literature data (Fig. S9, ESI $\dagger$ ). ${ }^{47}$ The absorption and PL spectra of BBIA in THF solution at a concentration of $10^{-5} \mathrm{M}$ are shown in Fig. 2(a). BBIA shows a vibronic spectrum (a)

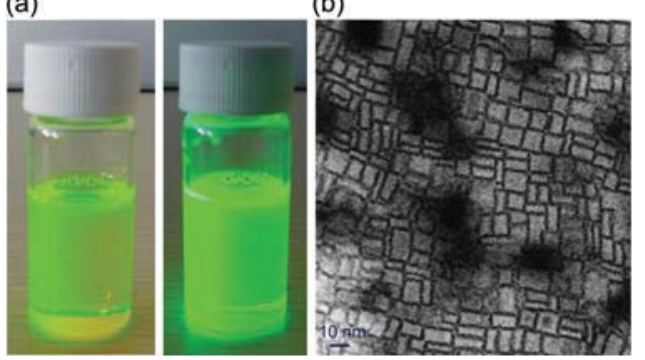

Fig. 1 (a) Photographs of the colloidal perovskite solution under visible (left) and UV (right) illumination. (b) Transmission electron micrograph of the nanocrystals.

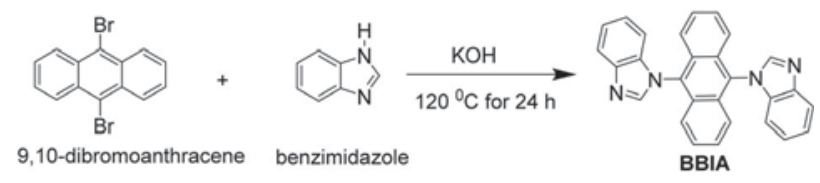

Scheme 1 Synthetic route to the BBIA compound.

with absorption peaks at 357,376 , and $396 \mathrm{~nm}$ corresponding to the $\pi \rightarrow \pi^{*}$ transitions of the anthracene core unit. ${ }^{49}$ The PL band is centered at $431 \mathrm{~nm}$ with a shoulder peak at around $417 \mathrm{~nm}$ when excited at $350 \mathrm{~nm}$. The optical bandgap $\left(E_{\mathrm{g}}\right)$ is therefore estimated to be $3.06 \mathrm{eV}$ from the intersection of the absorption and emission peaks, ${ }^{50}$ as summarized in Table 1.

We characterized the thermal decomposition temperature $\left(T_{\mathrm{d}}\right)$ of BBIA using thermogravimetric analysis (TGA), which provides a high $T_{\mathrm{d}}$ of $325{ }^{\circ} \mathrm{C}$, corresponding to $5 \%$ loss of the initial mass (Fig. 2(b)). The high thermal stability, which is a prerequisite for thermally evaporated ETMs, is possibly due to its non-coplanar structure and the rigid anthracene core. ${ }^{51,52}$ The electrochemical characteristics were next investigated using cyclic voltammetry (CV). The cyclic voltammogram was recorded using a glassy carbon working electrode, with ferrocene as the reference (Fig. 2(c)). The HOMO energy level of BBIA is determined from the oxidation potential $(-6.07 \mathrm{eV})$, and by subtracting the bandgap energy, the LUMO level is determined to be $-3.01 \mathrm{eV}$. The density functional theory (DFT) calculations were also carried out using the B3LYP* methods in the Amsterdam Density Functional (ADF) program with the TZP basis sets. As shown in Fig. 2(d), the HOMO and LUMO isosurfaces are mostly localized around the anthracene core with a small degree of extension towards the imidazole groups, implying that the substituted benzimidazole groups do not significantly influence the optical properties of the core anthracene unit. The DFTcalculated HOMO and LUMO levels are reasonably consistent with the experimental values, as shown in Table 1.

The electron mobility $\left(\mu_{\mathrm{e}}\right)$ of BBIA is characterized under an ambient atmosphere using the electron-only device, with the architecture of ITO $(120 \mathrm{~nm}) /$ BBIA or TPBi $(150 \mathrm{~nm}) / \mathrm{LiF}(1 \mathrm{~nm}) /$ Al $(100 \mathrm{~nm})$. Fig. 3a shows the current density $(J)$-voltage $(V)$ characteristics of BBIA and TPBi based electron-only devices. BBIA shows a higher current density and a significantly low turn-on voltage. Moreover, the electron mobility of BBIA is then estimated by the modified Mott-Gurney equation of the spacecharge-limited current (SCLC) based on the Poole Frenkel mobility model given by: ${ }^{53,54}$

$$
J=\frac{9}{8} \varepsilon \varepsilon_{0} \mu_{0} \frac{V\left(V-V_{\beta}\right)}{L^{3}} \exp \left(0.89 \gamma \sqrt{\frac{V}{L}}\right)
$$

where $\varepsilon_{0}$ is the vacuum permittivity $\left(\varepsilon_{0}=8.85 \times 10^{-12} \mathrm{~F} \mathrm{~m}^{-1}\right)$, $\varepsilon$ is the relative dielectric constant of the BBIA film (assumed to be 3.0), $\mu_{0}$ is the zero-field mobility, $L$ is the distance between the electrodes, $V_{\beta}$ is the correction term that has a theoretical value of $0.9 \mathrm{~V}$ for perfectly symmetric contacts, $\gamma$ is the parameter quantifying the mobility field dependence. The electron mobility can therefore be calculated for each voltage point by 
(a)

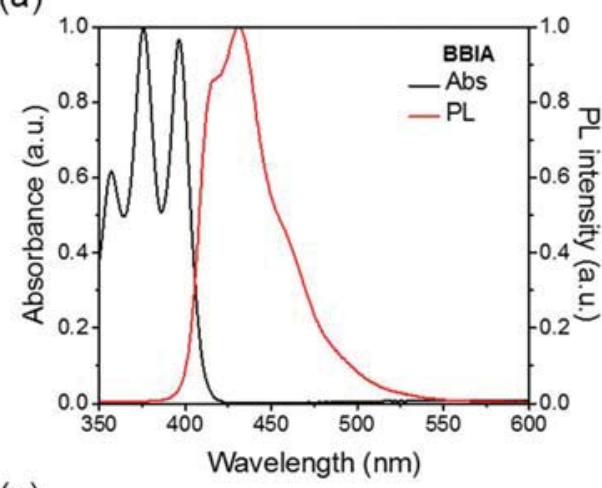

(c)

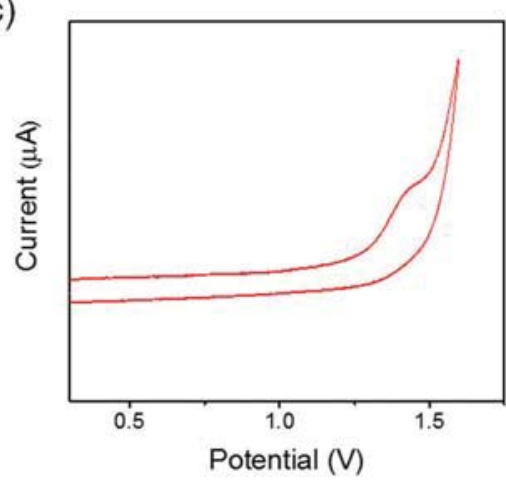

(b)

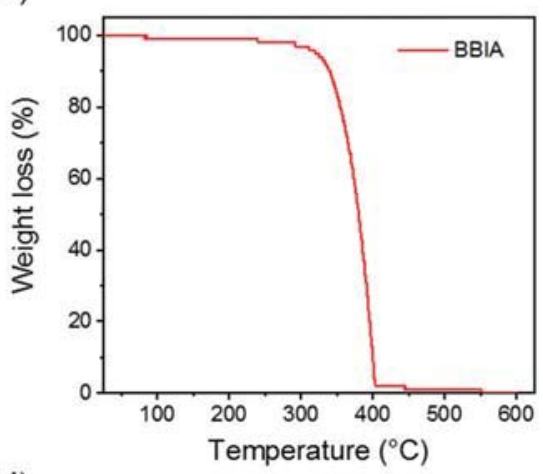

(d)

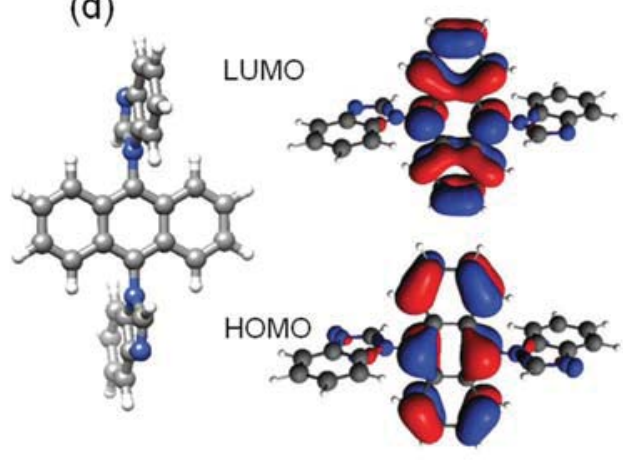

Fig. 2 Photophysical, thermal, and electrochemical properties of BBIA. (a) Absorbance and photoluminescence spectra of BBIA in THF solution (at $10^{-5}$ M). (b) Thermal decomposition temperature ( $T_{\mathrm{d}}$ ) of BBIA measured at a heating rate of $10^{\circ} \mathrm{C} \mathrm{min}^{-1}$. (c) Cyclic voltammogram of BBIA in THF solution (at $10^{-5} \mathrm{M}$ ). (d) Optimized molecular structure of BBIA and calculated spatial distributions of the HOMO and LUMO energy levels using the DFT calculations.

Table 1 Photophysical, electrochemical, and thermal characteristics of BBIA

\begin{tabular}{lllllllll}
\hline Compound & Absorbance $^{a}(\mathrm{~nm})$ & $\lambda_{\mathrm{PL}}{ }^{a}(\mathrm{~nm})$ & $E_{\mathrm{g}}{ }^{b}(\mathrm{eV})$ & $E_{\mathrm{Ox}}^{\text {onset } c}(\mathrm{~V})$ & $\mathrm{HOMO}^{d}(\mathrm{eV})$ & $\mathrm{LUMO}^{e}(\mathrm{eV})$ & $T_{\mathrm{d}}{ }^{f}\left({ }^{\circ} \mathrm{C}\right)$ & $\mu_{\mathrm{e}, \mathrm{SCLC}^{g}}\left(\mathrm{~cm}^{2} \mathrm{~V}^{-1} \mathrm{~s}^{-1}\right)$ \\
\hline BBIA & $357,376,396$ & 431 & 3.06 & 1.27 & $-6.07(-6.03)$ & $-3.01(-2.90)$ & 325 & $4.17 \times 10^{-4}$
\end{tabular}

${ }^{a}$ Characterized in THF solution with a concentration of $10^{-5}$ M. ${ }^{b}$ Estimated from the onset of the absorption spectrum. ${ }^{c}$ Semi-oxidation potential with ferrocene $(\mathrm{Fc})$ as the internal standard. ${ }^{d} E_{\mathrm{HOMO}}=-\left(E_{\mathrm{ox}}+4.8\right) .{ }^{e}$ Determined by subtracting the bandgap from the HOMO level, i.e. $E_{\mathrm{LUMO}}=\left(E_{\mathrm{HOMO}}+E_{\mathrm{g}}\right)$. The energy levels in parentheses were obtained by DFT computations. ${ }^{f}$ Thermal decomposition temperature when the mass decreases to $95 \%$ of the initial value. ${ }^{g}$ Electron mobility at an electric field of $10^{5} \mathrm{~V} \mathrm{~cm}^{-1}$.

(a)

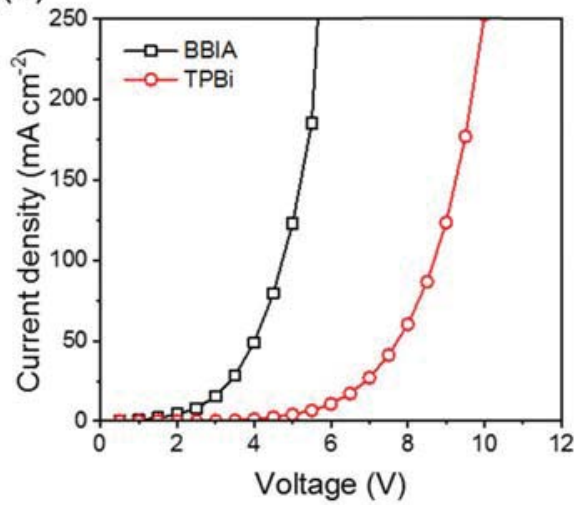

(b)

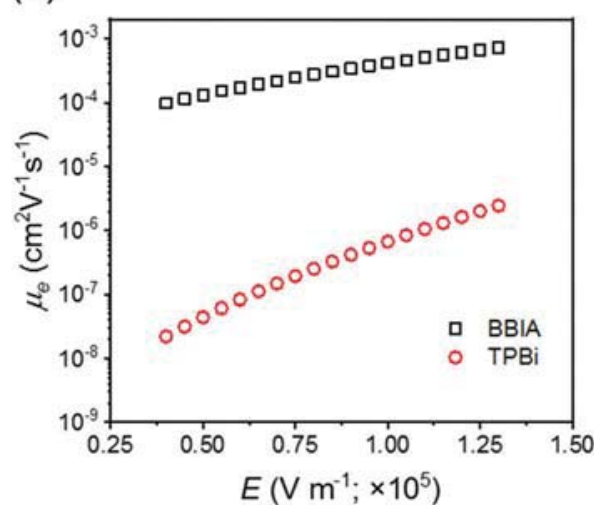

Fig. 3 Transport properties of BBIA and TPBi. (a) J-V characteristics of the electron-only device. (b) The calculated electron mobility as a function of electric field. 
Table 2 Effect of electron transporting materials, BBIA, TPBi, and BPhen on the EL characteristics of devices

\begin{tabular}{|c|c|c|c|c|c|c|c|c|}
\hline ETL & HTL & HCL & $V_{\text {on }}(\mathrm{V})$ at $10 \mathrm{~cd} \mathrm{~m}^{-2}$ & $\eta_{\mathrm{CE}}\left(\mathrm{cd} \mathrm{A}^{-1}\right)$ & $\eta_{\mathrm{PE}}\left(\operatorname{lm~} \mathrm{W}^{-1}\right)$ & $\eta_{\text {ext }}(\%)$ & $\lambda_{\mathrm{EL}}(\mathrm{FWHM})(\mathrm{nm})$ & $L_{\max }\left(\mathrm{cd} \mathrm{m}^{-2}\right)$ \\
\hline \multirow[t]{4}{*}{ BBIA } & 一 & - & 2.27 & 2.33 & 2.44 & 0.58 & $528(24.0)$ & 833 \\
\hline & Poly-TPD & - & 2.26 & 3.92 & 4.19 & 0.98 & $528(23.5)$ & 3322 \\
\hline & - & 3ТРYМВ & 2.34 & 8.83 & 11.10 & 2.18 & $528(23.6)$ & 1680 \\
\hline & Poly-TPD & 3ТРYМB & 2.35 & 12.2 & 12.8 & 2.96 & $528(23.3)$ & 4385 \\
\hline TPBi & Poly-TPD & 3ТРYМB & 3.20 & 6.25 & 5.32 & 1.51 & $528(23.6)$ & 2330 \\
\hline $\mathrm{Alq}_{3}$ & Poly-TPD & 3ТРYМB & 3.20 & 1.05 & 0.94 & 0.28 & $528(28.7)$ & 759 \\
\hline
\end{tabular}

linearly fitting the experimentally obtained $\ln \left[\frac{J}{V\left(V+V_{\beta}\right)}\right]$ with respect to $\sqrt{\frac{V}{L}}$ (ESI, $\dagger$ Fig. S3), yielding $\mu_{\mathrm{e}}$ versus electric field $E$ (Fig. 3(b)). Accordingly, the calculated zero-field $\mu_{\mathrm{e}}$ is $8.11 \times$ $10^{-6} \mathrm{~cm}^{2} \mathrm{~V}^{-1} \mathrm{~s}^{-1}$ and gradually increased to $\mu_{\mathrm{e}}=4.17 \times$ $10^{-4} \mathrm{~cm}^{2} \mathrm{~V}^{-1} \mathrm{~s}^{-1}$ at $E=10^{5} \mathrm{~V} \mathrm{~cm}^{-1}$, which is about three orders of magnitude higher than that of the standard benzimidazolebased ETM, such as TPBi $\left(\mu_{\mathrm{e}}=6.72 \times 10^{-7} \mathrm{~cm}^{2} \mathrm{~V}^{-1} \mathrm{~s}^{-1}\right.$ at $\left.E=1 \times 10^{5} \mathrm{~V} \mathrm{~cm}^{-1}\right)$. The $\mu_{\mathrm{e}}$ values of TPBi are also in line with those in the literature. ${ }^{55}$

We consider that BBIA is a good ETM due to its high thermal stability and high electron mobility. The LED devices were fabricated using colloidal perovskite nanocrystals as the emission layer (EML). First, the device architecture of ITO/PEDOT:PSS/ EML/BBIA/LiF/Al was tested, providing a current efficiency $\left(\eta_{\mathrm{CE}}\right)$ of $2.33 \mathrm{~cd} \mathrm{~A}^{-1}$ and an external quantum efficiency $\left(\eta_{\text {ext }}\right)$ of $0.58 \%$. In particular, a low turn-on voltage $\left(V_{\text {on }}\right)$ of $2.27 \mathrm{~V}$ is obtained, owing to the high electron mobility of BBIA. The devices emit at $528 \mathrm{~nm}$ with a FWHM of $24 \mathrm{~nm}$, in line with the PL features. By placing a thin hole transport material, poly(4-butylphenyldiphenylamine) (Poly-TPD), before the EML, $\eta_{\mathrm{CE}}$ and $\eta_{\mathrm{ext}}$ are increased to $3.92 \mathrm{~cd} \mathrm{~A}^{-1}$ and $0.98 \%$, respectively. The maximum luminance $\left(L_{\max }\right)$ also increases from 833 to $3322 \mathrm{~cd} \mathrm{~m}^{-2}$. The Poly-TPD layer confines the injected electrons in the EML due to the shallow LUMO energy level. ${ }^{56}$ We also tested deposition of an ultrathin $(5 \mathrm{~nm})$ hole confinement layer (HCL), 3TPYMB, after the EML, obtaining $\eta_{\mathrm{CE}}$ and $\eta_{\mathrm{ext}}$ of $8.83 \mathrm{~cd} \mathrm{~A}^{-1}$ and $2.18 \%$. Indeed, it has deep HOMO energy levels, so the $V_{\text {on }}$ is slightly increased from $2.26 \mathrm{~V}$ to $2.34 \mathrm{~V}$ (Table 2). All together, the $\eta_{\mathrm{CE}}$ and $\eta_{\text {ext }}$ values reached $12.2 \mathrm{~cd} \mathrm{~A}^{-1}$ and $2.96 \%$, respectively, by depositing a $20 \mathrm{~nm}$ Poly-TPD layer before the EML and a $5 \mathrm{~nm}$ 3TPYMB hole confining layer after the EML (for schematic device architecture see the ESI, $\dagger$ Fig. S4). The maximum power efficiency is $12.8 \mathrm{~lm} \mathrm{~W}^{-1}$. The optimized device architecture containing the BBIA ETM also shows only an efficiency roll-off (a)

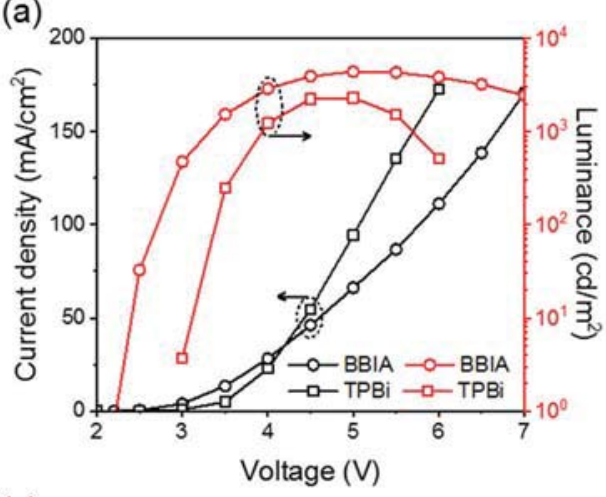

(c)

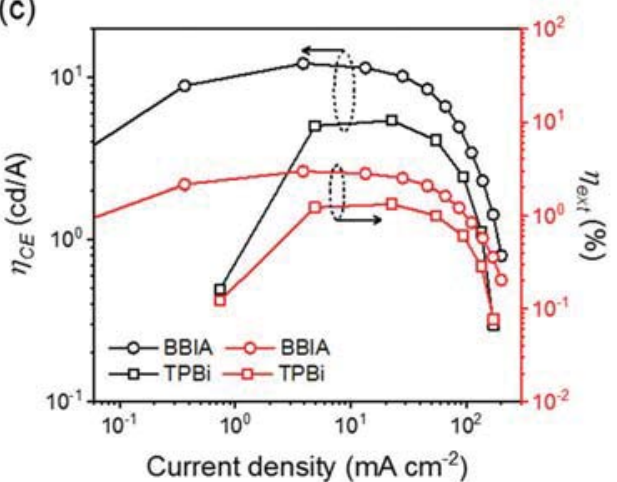

(b)

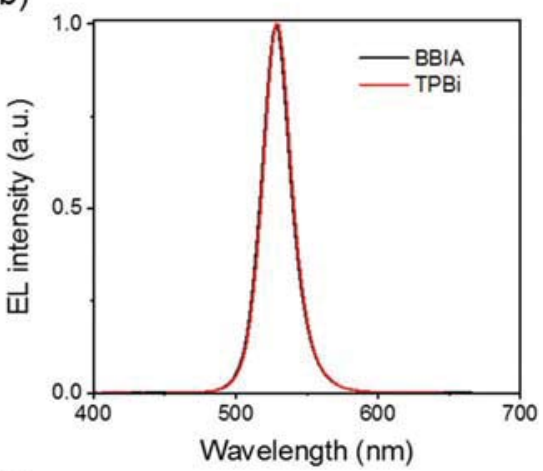

(d)

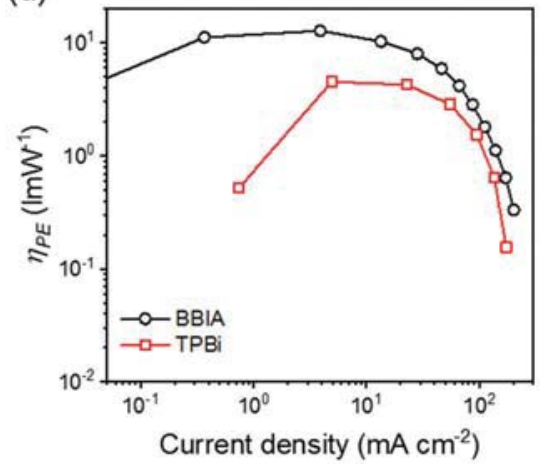

Fig. 4 LED characteristics using different ETMs. (a) Current density and luminance as a function of voltage. (b) EL spectra. (c) Current efficiency and external quantum efficiency as a function of current density. (d) Power efficiency as a function of current density. 
(a)

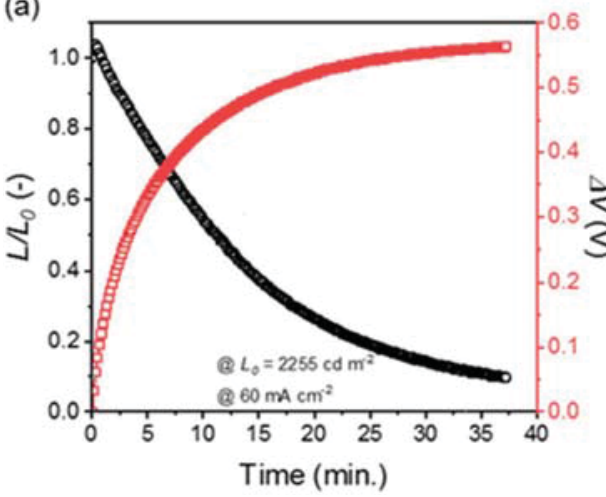

(b)

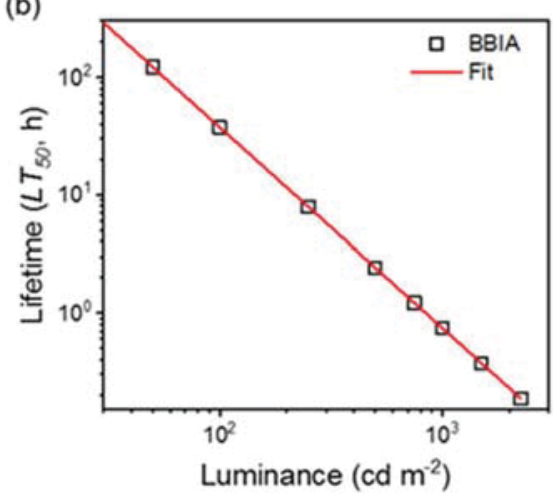

Fig. 5 Operational stability of the perovskite nanocrystal LEDs using BBIA as the ETM. (a) Relative luminance and driving voltage as a function of time under continuous electrical stress at a constant current density of $60 \mathrm{~mA} \mathrm{~cm}{ }^{-2}$, corresponding to the initial luminance ( $\left.L_{0}\right)$ of 2255 cd $\mathrm{m}^{-2}$. (b) Extrapolated $L T_{50}$ as a function of $L_{0}$, showing a $L T_{50}$ of $\sim 37$ hours at $L_{0}=100 \mathrm{~cd} \mathrm{~m}^{-2}$.

of $8 \pm 1 \%$ at a high luminance of $2000 \mathrm{~cd} \mathrm{~m}^{-2}$ due to the balanced charge injection in the EML. ${ }^{57,58}$ The control devices fabricated using standard ETMs (TPBi and $\mathrm{Alq}_{3}$ ), on the other hand, exhibit lower efficiencies, $\eta_{\text {ext }}$ becomes $1.51 \%$ and $0.28 \%$ for TPBi and $\mathrm{Alq}_{3}$, respectively (see Table 2). We attribute the poor efficiencies in $\mathrm{Alq}_{3}$-based devices to its low electron mobility, $0.62 \times 10^{-8} \mathrm{~cm}^{2} \mathrm{~V}^{-1} \mathrm{~s}^{-1} \cdot{ }^{59}$

More specifically, the current density-voltage-luminance $(J-V-L)$ characteristics of the devices using BBIA and TPBi ETMs are shown in Fig. 4(a). BBIA-based devices show a lower turn-on-voltage $\left(V_{\text {on }}\right)$ than the TPBi counterpart, suggesting the improved electron injection, because of: (i) a lower electron injection barrier by $0.31 \mathrm{eV}$ and (ii) an over 600 -fold increase of electron mobility $\left(6.72 \times 10^{-7} \mathrm{~cm}^{2} \mathrm{~V}^{-1} \mathrm{~s}^{-1}\right.$ at $E=1 \times$ $10^{5} \mathrm{~V} \mathrm{~cm}^{-1}$ ). Unexpectedly, TPBi-based devices exhibit a higher current density than BBIA-based devices. As the LUMO level for TPBi $(\sim 2.7 \mathrm{eV})$ is higher than that for BBIA $(\sim 3.0 \mathrm{eV})$, we attribute this to the high degree of charge carrier imbalance in the EML due to the electron accumulation at the ETL/cathode interface. ${ }^{60,61}$ We notice that there are a number of reports on high current densities even with low-mobility ETMs, such as $\mathrm{Alq}_{3} \cdot{ }^{31,62}$ Further mechanistic studies will be required to reveal the root cause. Both devices exhibit nearly identical EL spectra (Fig. 4(b)). Fig. 4(c) and (d) show the corresponding $\eta_{\mathrm{CE}}, \eta_{\text {ext }}$ and $\eta_{\mathrm{PE}}$ as a function of current density. As expected, BBIA-based devices show higher efficiencies than TPBi-based devices. The devices also exhibit very consistent corresponding emission maxima throughout the operating range (ESI, $\dagger$ Fig. S5). The devices show an ultra-pure green emission with the International Commission on Illumination (CIE) 1931 coordinates of $(0.172$, 0.765 ) which covers $>95 \%$ coverage of the Recommendation (Rec.) 2020 standard.

Finally, the operational lifetime of BBIA-based perovskite nanocrystal LEDs was investigated. The encapsulated device shows an $\mathrm{LT}_{50}$, the operational time before reaching $50 \%$ of its initial luminance $\left(L_{0}\right)$, of 0.19 hours at a constant driving current density of $60 \mathrm{~mA} \mathrm{~cm}{ }^{-2}$ corresponding to an $L_{0}$ of $2255 \mathrm{~cd} \mathrm{~m}^{-2}$ (Fig. 5a). A relatively small increase of the operating voltage, $0.56 \mathrm{~V}$, which is often desired to maintain the stable current density throughout the measurement, is observed. By using the brightness acceleration factor $(m)$ of 1.5 in the empirical formula of $L_{0}^{m} \times \mathrm{LT}=$ constant, ${ }^{63}$ we determine the $\mathrm{LT}_{50}$ value of the device at $L_{0}=100 \mathrm{~cd} \mathrm{~m}^{-2}$ to be $\sim 37$ hours (Fig. $5 \mathrm{~b}$ ). In comparison, the PerLED devices based on conventional TPBi exhibit an $\mathrm{LT}_{50}$ value of 0.13 hours at a lower current density of $20 \mathrm{~mA} \mathrm{~cm}^{-2}$ (Fig. S6, ESI†).

\section{Conclusions}

In conclusion, we have developed efficient perovskite nanocrystal LEDs using a new ETM, BBIA, with two n-type $1 H$-benzimidazole units covalently bound to the C9 and C10 positions of an anthracene core, exhibiting a high electron mobility of $4.17 \times$ $10^{-4} \mathrm{~cm}^{2} \mathrm{~V}^{-1} \mathrm{~s}^{-1}$. BBIA-based devices exhibit high color purity with high $\eta_{\mathrm{CE}}$ and $\eta_{\mathrm{ext}}$ of $12.2 \mathrm{~cd} \mathrm{~A}^{-1}$ and $2.96 \%$, respectively. More importantly, there is only $\sim 8 \pm 1 \%$ efficiency roll-off at $2000 \mathrm{~cd} \mathrm{~m}^{-2}$. We consider the ETM as a promising candidate for high-performance perovskite LEDs.

\section{Experimental}

\section{Materials}

Patterned indium tin oxide (ITO) coated glass substrates with a sheet resistance of $15 \Omega \square^{-1}$ were purchased from Lumtech Corp. Poly(3,4-ethylene-dioxythiophene)-poly(styrene sulfonate) (PEDOT: PSS, Clevios AI 4083) was purchased from Heraeus. The GPC grade hole transporting material, poly[ $N, N^{\prime}$-bis(4-butylphenyl)- $N, N^{\prime}$-bis(phenyl)-benzidine] (Poly-TPD) was procured from Lumtech Corp. The neutral low- $k$ host matrix poly methyl methacrylate (PMMA, average M.W. 350 000) was supplied by Sigma-Aldrich. Ultrapure sublimed grade electron transporting materials $2,2^{\prime}, 2^{\prime \prime}-(1,3,5-$ benzinetriyl)-tris(1-phenyl-1- $H$-benzimidazole) (TPBi), tris(8-hydroxyquinoline)aluminum, and tris(2,4,6-trimethyl-3-(pyridin-3-yl)phenyl)borane (3TPYMB) were procured from Lumtech corp. Lithium fluoride (LiF, 99.98\%) was purchased from Lumtech corp. and Acros Organics. Aluminum (Al) pellets (99.999\%) were obtained from Kurt J. Lesker Co. Ltd. The above materials were used as received without any further purification. 


\section{Materials characterization}

The absorbance spectrum of BBIA in THF solution was collected using a JASCO V670 spectrometer. The PL spectrum of BBIA was recorded using a Hamamatsu CCD spectrometer (wavelength resolution $<2 \mathrm{~nm}$ ) at an excitation wavelength of $350 \mathrm{~nm}$. The absolute PLQY values were determined in an integrating sphere using a commercial model, Hamamatsu Quantaurus QY C11347-11 with an excitation wavelength of $375 \mathrm{~nm}$. X-rays diffraction (XRD) patterns of 2D perovskites were collected using a PANalytical X'Pert PRO-MPD diffractometer with $\mathrm{Cu}-\mathrm{K} \alpha$ radiation. The data were recorded in the range of $5-70^{\circ} 2 \theta$ at room temperature with an angular step size of $0.05^{\circ}$ and a counting time of 0.23 seconds per step. The TEM images of perovskite NCs were captured under cryogenic conditions using an STEM (Hitachi HD 2700) equipped with a cryo-holder (liquid nitrogen) with high beam acceleration voltages from 80 to $200 \mathrm{kV}$. A surface profiler (DektakXT Bruker) was used to evaluate the film thickness of various device layers.

\section{Device fabrication}

Firstly, the patterned ITO coated glass substrates were sequentially sonicated in diluted neutral Extran MA solution, acetone, and isopropyl alcohol, each for 20 minutes. Subsequently, these substrates were dried using a nitrogen gun, and exposed to oxygen plasma for 10 minutes. The hole injection layer, PEDOT:PSS, was deposited through spin-coating and then annealed at $130{ }^{\circ} \mathrm{C}$ for 30 minutes in an ambient atmosphere. Then the substrates were transferred to a nitrogen filled glove to spin-coat a PolyTPD hole transporting layer and an electron injection layer. After 30 minutes of annealing at $130{ }^{\circ} \mathrm{C}$, the perovskite emissive layer was deposited through the spin-casting method. Later on, these substrates were transferred to a high vacuum thermal evaporation chamber and 3TPYMB (HCL), an ETL (BBIA, TPBi, and $\mathrm{Alq}_{3}$ ), a $\mathrm{LiF}$ electron injection layer, and an $\mathrm{Al}$ cathode successively. The active area $0.25 \mathrm{~cm}^{2}$ of the devices was defined by the overlapping area between the ITO and Al layers.

\section{PerLED characterization}

The $J-V-L$ characteristics of the PerLEDs were measured using a Keithley $2400 \mathrm{SMU}$ source meter at room temperature under ambient conditions and a Photo Research PR 655 spectroradiometer. The EL spectra and CIE color coordinates of the devices were also recorded by using a PR 655 spectroradiometer. The $\eta_{\text {ext }}$ was calculated as the total number of emitted photons divided by the total number of injected electrons by assuming a Lambertian-type emission pattern. The operational lifetime of PerLED devices was measured using a smart Ossila Lifetime System (E642) under a constant current.

\section{Author's contributions}

KMF initiated the collaboration with CJS. SK, CJS, and KMF conceived the project. SIV, PhD student in the group of KMF has synthesized BBIA and analyzed structural and thermal properties. JJ synthesized the colloidal perovskite NCs. SK characterized the photophysical properties. SK and TM fabricated and characterized the PeLEDs and electron only devices. SK designed the experiments and interpreted the data. SK and CJS wrote the manuscript. All authors discussed the results and commented on the manuscript.

\section{Conflicts of interest}

There are no conflicts to declare.

\section{Acknowledgements}

The authors are grateful for financial support from ETH startup funding and the Swiss National Science Foundation (project number: 200021-178944). The authors thank Dr Frank Krumeich for TEM analysis and Dr Reinhard O. Kissner for CV analysis. KMF thanks the University of Fribourg and the Fribourg Center for Nanomaterials, FriMat, for generous support. SIV is grateful to the Swiss National Science Foundation for a mobility grant (P1FRP2_178150).

\section{References}

1 B. R. Sutherland and E. H. Sargent, Nat. Photonics, 2016, 10, 295.

2 Z.-K. Tan, R. S. Moghaddam, M. L. Lai, P. Docampo, R. Higler, F. Deschler, M. Price, A. Sadhanala, L. M. Pazos, D. Credgington, F. Hanusch, T. Bein, H. J. Snaith and R. H. Friend, Nat. Nanotechnol., 2014, 9, 687.

3 Y.-H. Kim, H. Cho and T.-W. Lee, Proc. Natl. Acad. Sci. U. S. A., 2016, 113, 11694-11702.

4 J. Jagielski, S. Kumar, W.-Y. Yu and C.-J. Shih, J. Mater. Chem. C, 2017, 5, 5610-5627.

5 Q. A. Akkerman, G. Rainò, M. V. Kovalenko and L. Manna, Nat. Mater., 2018, 17, 394-405.

6 J. Jagielski, S. Kumar, M. Wang, D. Scullion, R. Lawrence, Y.-T. Li, S. Yakunin, T. Tian, M. V. Kovalenko, Y.-C. Chiu, E. J. G. Santos, S. Lin and C.-J. Shih, Sci. Adv., 2017, 3, eaaq0208.

7 Y.-H. Kim, J. S. Kim and T.-W. Lee, Adv. Mater., 2018, 1804595.

8 M.-H. Park, J. S. Kim, J.-M. Heo, S. Ahn, S.-H. Jeong and T.-W. Lee, ACS Energy Lett., 2019, 4, 1134-1149.

9 M.-H. Park, S.-H. Jeong, H.-K. Seo, C. Wolf, Y.-H. Kim, H. Kim, J. Byun, J. S. Kim, H. Cho and T.-W. Lee, Nano Energy, 2017, 42, 157-165.

10 K. Lin, J. Xing, L. N. Quan, F. P. G. de Arquer, X. Gong, J. Lu, L. Xie, W. Zhao, D. Zhang, C. Yan, W. Li, X. Liu, Y. Lu, J. Kirman, E. H. Sargent, Q. Xiong and Z. Wei, Nature, 2018, 562, 245-248.

11 T. Chiba, Y. Hayashi, H. Ebe, K. Hoshi, J. Sato, S. Sato, Y.-J. Pu, S. Ohisa and J. Kido, Nat. Photonics, 2018, 12, 681-687.

12 M.-H. Park, J. Park, J. Lee, H. S. So, H. Kim, S.-H. Jeong, T.-H. Han, C. Wolf, H. Lee, S. Yoo and T.-W. Lee, Adv. Funct. Mater., 2019, 29, 1902017.

13 B. Zhao, S. Bai, V. Kim, R. Lamboll, R. Shivanna, F. Auras, J. M. Richter, L. Yang, L. Dai, M. Alsari, X.-J. She, L. Liang, 
J. Zhang, S. Lilliu, P. Gao, H. J. Snaith, J. Wang, N. C. Greenham, R. H. Friend and D. Di, Nat. Photonics, 2018, 12, 783-789.

14 Y. Jiang, C. Qin, M. Cui, T. He, K. Liu, Y. Huang, M. Luo, L. Zhang, H. Xu, S. Li, J. Wei, Z. Liu, H. Wang, G.-H. Kim, M. Yuan and J. Chen, Nat. Commun., 2019, 10, 1868.

15 J. Shamsi, A. S. Urban, M. Imran, L. De Trizio and L. Manna, Chem. Rev., 2019, 119, 3296-3348.

16 L. N. Quan, F. P. García de Arquer, R. P. Sabatini and E. H. Sargent, Adv. Mater., 2018, 30, 1801996.

17 S. A. Veldhuis, P. P. Boix, N. Yantara, M. Li, T. C. Sum, N. Mathews and S. G. Mhaisalkar, Adv. Mater., 2016, 28, 6804-6834.

18 M. Lu, Y. Zhang, S. Wang, J. Guo, W. W. Yu and A. L. Rogach, Adv. Funct. Mater., 2019, 1902008.

19 S. Kumar, J. Jagielski, N. Kallikounis, Y.-H. Kim, C. Wolf, F. Jenny, T. Tian, C. J. Hofer, Y.-C. Chiu, W. J. Stark, T.-W. Lee and C.-J. Shih, Nano Lett., 2017, 17, 5277-5284.

20 S. Kumar, J. Jagielski, T. Tian, N. Kallikounis, W.-C. Lee and C.-J. Shih, ACS Energy Lett., 2019, 4, 118-125.

21 A. Perumal, S. Shendre, M. Li, Y. K. E. Tay, V. K. Sharma, S. Chen, Z. Wei, Q. Liu, Y. Gao, P. J. S. Buenconsejo, S. T. Tan, C. L. Gan, Q. Xiong, T. C. Sum and H. V. Demir, Sci. Rep., 2016, 6, 36733.

22 T. Chiba, K. Hoshi, Y.-J. Pu, Y. Takeda, Y. Hayashi, S. Ohisa, S. Kawata and J. Kido, ACS Appl. Mater. Interfaces, 2017, 9, 18054-18060.

23 F. Yan, J. Xing, G. Xing, L. Quan, S. T. Tan, J. Zhao, R. Su, L. Zhang, S. Chen, Y. Zhao, A. Huan, E. H. Sargent, Q. Xiong and H. V. Demir, Nano Lett., 2018, 18, 3157-3164.

24 L.-P. Cheng, J.-S. Huang, Y. Shen, G.-P. Li, X.-K. Liu, W. Li, Y.-H. Wang, Y.-Q. Li, Y. Jiang, F. Gao, C.-S. Lee and J.-X. Tang, Adv. Opt. Mater., 2019, 7, 1801534.

25 M. Abdi-Jalebi, Z. Andaji-Garmaroudi, S. Cacovich, C. Stavrakas, B. Philippe, J. M. Richter, M. Alsari, E. P. Booker, E. M. Hutter, A. J. Pearson, S. Lilliu, T. J. Savenije, H. Rensmo, G. Divitini, C. Ducati, R. H. Friend and S. D. Stranks, Nature, 2018, 555, 497.

26 S. D. Stranks, ACS Energy Lett., 2017, 2, 1515-1525.

27 I. L. Braly, D. W. deQuilettes, L. M. Pazos-Outón, S. Burke, M. E. Ziffer, D. S. Ginger and H. W. Hillhouse, Nat. Photonics, 2018, 12, 355-361.

28 Y.-K. Chih, J.-C. Wang, R.-T. Yang, C.-C. Liu, Y.-C. Chang, Y.-S. Fu, W.-C. Lai, P. Chen, T.-C. Wen, Y.-C. Huang, C.-S. Tsao and T.-F. Guo, Adv. Mater., 2016, 28, 8687-8694.

29 J. C. Yu, D. W. Kim, D. B. Kim, E. D. Jung, K.-S. Lee, S. Lee, D. D. Nuzzo, J.-S. Kim and M. H. Song, Nanoscale, 2017, 9, 2088-2094.

30 S. Liu, H. Yu, Q. Zhang, F. Qin, X. Zhang, L. Zhang and W. Xie, J. Mater. Chem. C, 2019, 7, 5426-5432.

31 C. V. Hoven, R. Yang, A. Garcia, V. Crockett, A. J. Heeger, G. C. Bazan and T.-Q. Nguyen, Proc. Natl. Acad. Sci. U. S. A., 2008, 105, 12730-12735.

32 N. F. Jamaludin, N. Yantara, Y. F. Ng, A. Bruno, B. K. Chandran, X. Y. Chin, K. Thirumal, N. Mathews, C. Soci and S. Mhaisalkar, J. Mater. Chem. C, 2018, 6, 2295-2302.

33 H. Ye, D. Chen, M. Liu, S.-J. Su, Y.-F. Wang, C.-C. Lo, A. Lien and J. Kido, Adv. Funct. Mater., 2014, 24, 3268-3275.
34 N. Seidler, S. Reineke, K. Walzer, B. Lüssem, A. Tomkeviciene, J. V. Grazulevicius and K. Leo, Appl. Phys. Lett., 2010, 96, 093304.

35 H. Lee, M.-J. Maeng, J.-A. Hong, R. Najnin, J. Moon, H. Cho, J. Lee, B.-G. Yu, Y. Park and N. S. Cho, J. Mater. Chem. C, 2017, 5, 9911-9919.

36 J.-H. Lee, S.-H. Cheng, S.-J. Yoo, H. Shin, J.-H. Chang, C.-I. Wu, K.-T. Wong and J.-J. Kim, Adv. Funct. Mater., 2015, 25, 361-366.

37 V. I. Adamovich, S. R. Cordero, P. I. Djurovich, A. Tamayo, M. E. Thompson, B. W. D'Andrade and S. R. Forrest, Org. Electron., 2003, 4, 77-87.

38 X. Jin, C. Chang, W. Zhao, S. Huang, X. Gu, Q. Zhang, F. Li, Y. Zhang and Q. Li, ACS Appl. Mater. Interfaces, 2018, 10, 15803-15811.

39 J.-S. Park, J. Kyhm, H. H. Kim, S. Jeong, J. Kang, S.-E. Lee, K.-T. Lee, K. Park, N. Barange, J. Han, J. D. Song, W. K. Choi and I. K. Han, Nano Lett., 2016, 16, 6946-6953.

40 F. Jin, B. Zhao, B. Chu, H. Zhao, Z. Su, W. Li and F. Zhu, J. Mater. Chem. C, 2018, 6, 1573-1578.

41 Y. Ling, Z. Yuan, Y. Tian, X. Wang, J. C. Wang, Y. Xin, K. Hanson, B. Ma and H. Gao, Adv. Mater., 2016, 28, 305-311.

42 Y. Meng, M. Ahmadi, X. Wu, T. Xu, L. Xu, Z. Xiong and P. Chen, Org. Electron., 2019, 64, 47-53.

43 X. Y. Chin, A. Perumal, A. Bruno, N. Yantara, S. A. Veldhuis, L. Martínez-Sarti, B. Chandran, V. Chirvony, A. S.-Z. Lo, J. So, C. Soci, M. Grätzel, H. J. Bolink, N. Mathews and S. G. Mhaisalkar, Energy Environ. Sci., 2018, 11, 1770-1778.

44 A. Kojima, K. Teshima, Y. Shirai and T. Miyasaka, J. Am. Chem. Soc., 2009, 131, 6050-6051.

45 L. Meng, E.-P. Yao, Z. Hong, H. Chen, P. Sun, Z. Yang, G. Li and Y. Yang, Adv. Mater., 2017, 29, 1603826.

46 J. Liu, Y. Xue, Z. Wang, Z.-Q. Xu, C. Zheng, B. Weber, J. Song, Y. Wang, Y. Lu, Y. Zhang and Q. Bao, ACS Nano, 2016, 10, 3536-3542.

47 L. Li, T.-L. Hu, J.-R. Li, D.-Z. Wang, Y.-F. Zeng and X.-H. Bu, CrystEngComm, 2007, 9, 412-420.

48 S. I. Vasylevskyi, K. Regeta, A. Ruggi, S. Petoud, C. Piguet and K. M. Fromm, Dalton Trans., 2018, 47, 596-607.

49 C.-H. Chien, C.-K. Chen, F.-M. Hsu, C.-F. Shu, P.-T. Chou and C.-H. Lai, Adv. Funct. Mater., 2009, 19, 560-566.

50 J.-H. Jou, S. Kumar, P.-H. Fang, A. Venkateswararao, K. R. J. Thomas, J.-J. Shyue, Y.-C. Wang, T.-H. Li and H.-H. Yu, J. Mater. Chem. C, 2015, 3, 2182-2194.

51 J. Huang, J.-H. Su and H. Tian, J. Mater. Chem., 2012, 22, 10977-10989.

52 H. Park, J. Lee, I. Kang, H. Y. Chu, J.-I. Lee, S.-K. Kwon and Y.-H. Kim, J. Mater. Chem., 2012, 22, 2695-2700.

53 T. Yasuda, Y. Yamaguchi, D.-C. Zou and T. Tsutsui, Jpn. J. Appl. Phys., 2002, 41, 5626-5629.

54 S. M. H. Rizvi and B. Mazhari, J. Appl. Phys., 2017, 121, 155501.

55 Q. Zhang, B. Wang, J. Tan, G. Mu, W. Yi, X. Lv, S. Zhuang, W. Liu and L. Wang, J. Mater. Chem. C, 2017, 5, 8516-8526.

56 N. C. Erickson and R. J. Holmes, Adv. Funct. Mater., 2013, 23, 5190-5198. 
57 J.-H. Jou, S. Kumar, A. Agrawal, T.-H. Li and S. Sahoo, J. Mater. Chem. C, 2015, 3, 2974-3002.

58 W. Zou, R. Li, S. Zhang, Y. Liu, N. Wang, Y. Cao, Y. Miao, M. Xu, Q. Guo, D. Di, L. Zhang, C. Yi, F. Gao, R. H. Friend, J. Wang and W. Huang, Nat. Commun., 2018, 9, 608.

59 M. Ramar, P. Tyagi, C. K. Suman and R. Srivastava, RSC Adv., 2014, 4, 51256-51261.
60 Y.-H. Chen, D.-G. Ma, H.-D. Sun, J.-S. Chen, Q.-X. Guo, Q. Wang and Y.-B. Zhao, Light: Sci. Appl., 2016, 5, e16042.

61 F. So and D. Kondakov, Adv. Mater., 2010, 22, 3762-3777.

62 S. H. Rhee, K. b. Nam, C. S. Kim, M. Song, W. Cho, S.-H. Jin and S. Y. Ryu, ECS Solid State Lett., 2014, 3, R19-R22.

63 X. Dai, Z. Zhang, Y. Jin, Y. Niu, H. Cao, X. Liang, L. Chen, J. Wang and X. Peng, Nature, 2014, 515, 96. 